\title{
Back Calculation of Leakage Accident Source Term of Liquid Ammonia Gas Storage Tank
}

\author{
Chang Liu ${ }^{1}$, Teng $\mathrm{Su}^{1}$ and $\mathrm{Ru} \mathrm{Zhou}^{1 *}$ \\ ${ }^{1}$ College of Safety Science and Engineering, Nanjing Tech University, Nanjing, Jiangsu, 211816, China
}

\begin{abstract}
Ammonia is a colorless and toxic gas. Due to its fast leakage rate, the leakage port is not easy to detect, and it is often difficult to seal it, causing more serious personal injuries and property losses. So it is a key problem to predict the intensity and location of toxic and harmful gas leakage quickly and accurately. Then it needs to combine the atmospheric diffusion model and optimization algorithm to establish the source term information back calculation model, and solve the location and intensity of the leakage source based on the concentration data of the downwind direction of the leakage source. Based on the analysis of the physical and chemical properties of ammonia, according to Wilson plume rising experience formula and Gauss plume model, the leakage model of liquid ammonia storage tank is established, and the effective monitoring points are extracted. According to the concentration of simulated monitoring points, the source information is calculated by particle swarm optimization algorithm. The feasibility of this method in the leakage of liquid ammonia storage tank is verified, which can help emergency response of accidents.
\end{abstract}

\section{Introduction}

According to the relevant accident statistics, more than half of the hazardous chemical accidents are caused by explosion or release of hazardous chemicals ${ }^{[1]}$, because the leakage source and substance cannot be quickly identified, causing a certain range of social panic. More and more leakage accidents in the world have prompted scholars from all over the world to study the traceability of hazardous chemical leakage accidents. In China, from 1949 to 2002, a total of 51 major (special) leakage accidents occurred in China, including 8 liquid ammonia leakage accidents, with a frequency of $15.69 \%{ }^{[2]}$. In this paper, the source term information of non-heavy gas diffusion is studied, and the leakage of liquid ammonia storage tank is simulated by MATLAB. Based on the concentration of downwind monitoring point, the optimization algorithm is used to solve the source intensity and leakage position.

When there are holes or cracks on the tank top or above the liquid level, the gas in the tank leaks rapidly under the pressure. At this time, the leakage rate is calculated according to the gas phase leakage formula ${ }^{[3]}$. At this time, the whole leakage process can be regarded as continuous leakage, and the Gaussian plume model is used to simulate the gas diffusion.

At present, most of the gas diffusion models are improved on the basis of Gaussian model and extended to other fields to meet the needs of different scenes. Peng He et al. ${ }^{[4]}$ improved the Gaussian plume model of continuous leakage by increasing atmospheric humidity factor, gravitational subsidence factor and ground reflection coefficient, and combined vector machine and radial basis function to construct a classifier to predict the evolution of PM2.5, and finally combined the data from the Wuhan fixed monitoring station was verified. Qiong Zhang et al. ${ }^{[5]}$ considered the mixed layer height, dry deposition, wet deposition, radioactive decay and other factors, and used a modified Gaussian plume model to predict the concentration distribution of radionuclides. Boknam Lee et al. ${ }^{[6]}$ developed a forest fire smoke diffusion prediction system, based on grid geographic information system, forest maps, weather research and prediction models, and used Gaussian plume models to simulate local fire smoke diffusion. In addition to mathematical models, Computational Fluid Dynamics (Computational Fluid Dynamics, CFD) has been applied more and more widely in recent years. Many scholars have carried out related research on gas diffusion, Efthimiou et al. ${ }^{[7]}$ The CFDRans method is used to simulate the diffusion of harmful gas substances released in actual accidents in industrial facilities. Kumar et al. ${ }^{[8]}$ used CFD and Fluidyn PANACHE to accurately simulate the short-range plume diffusion of harmful pollutants in urban areas with complex geometric structures. Lin et al. ${ }^{[9]}$ used the CFD method to simulate the diffusion of a large number of vehicle pollutants in nearby road buildings when the traffic flow was too large. Despite widespread in the CFD model of atmospheric diffusion and application of high precision, but in emergency rescue, because the CFD modeling is more complex, often need to model in advance, and the CFD model and source term back calculation model incorporates a high degree of difficulty operating. For a long time, the Gaussian model is still the most used in the forward diffusion model and gas diffusion

*Corresponding author's e-mail: maxmuse.zhou@njtech.edu.cn 
prediction of the source term information back calculation. The above-mentioned scholars all use the Gaussian plume model for continuous leakage, but the applicable object of the Gaussian plume model is neutral gas, and fire smoke, PM2.5, etc. are obviously not, so it needs to be targeted for different application scenarios and objects. The improvements made are to increase the accuracy of the model and expand its scope of application by adding correction factors and modifying parameters. Therefore, the forward gas diffusion model in the back calculation of source term information in this paper needs to be revised to the standard Gaussian plume model and applied to the source term back calculation.

In the back calculation of gas source terms, Monache LD et al. ${ }^{[10]}$ reconstructed the pollution source based on Bayesian inference of Markov chain Monte Carlo, predicted a radioactive leakage accident, and ran Bayesian on a large parallel cluster. The algorithm gets the inversion result. Zheng $\mathrm{X}$ et al. ${ }^{[11]}$ used the pattern search method to study the setting of monitoring points for inverse calculation of source item information.

In this paper, the particle swarm optimization algorithm is used to analysis the source term inverse calculation of gas diffusion in liquid ammonia tank.

\section{Source term back calculation research}

\subsection{Leakage source model of liquid ammonia}

According to the physical and chemical properties of ammonia in Table 1 and formula (1) ${ }^{[3]}$, then the storage pressure in the actual production of liquid ammonia tank is generally $1.6 \mathrm{Mpa}$, when the small hole with a diameter of $20 \mathrm{~mm}$ leaks, the leakage rate should be $4.12 \mathrm{~kg} / \mathrm{s}$.

Table 1. Physical and chemical properties of ammonia.

\begin{tabular}{ccccccc}
\hline & $\begin{array}{c}\text { Molecular } \\
\text { weight, } \mathrm{g} / \mathrm{mol}\end{array}$ & Density, g/L & $\begin{array}{c}\text { Critical } \\
\text { pressure, MPa }\end{array}$ & Critical temperature, ${ }^{\circ} \mathrm{C}$ & $\begin{array}{c}\text { Saturated vapor } \\
\text { pressure, }{ }^{\circ} \mathrm{C}\end{array}$ & $\begin{array}{c}\text { Adiabatic index } \\
\text { of gas }\end{array}$ \\
\hline Ammonia & 17.3 & 0.771 & 11.4 & 132.5 & $20.33\left(50{ }^{\circ} \mathrm{C}\right)$ & 1.313 \\
\hline
\end{tabular}

$$
Q_{G}=Y C_{0} A P \sqrt{\frac{M \gamma}{R T_{G}}\left(\frac{2}{\gamma+1}\right)^{\frac{\gamma+1}{\gamma-1}}}
$$

Where: $\gamma$ is the adiabatic index of the gas; $Q_{G}$ is the gas leakage rate, $\mathrm{kg} / \mathrm{s} ; A$ is the split area, $\mathrm{m}^{2} ; Y$ is the outflow coefficient, $\mathrm{y}=0.1$ for critical flow; $C_{0}$ is the gas leakage coefficient; $M$ is the molar mass of the substance, $\mathrm{kg} / \mathrm{mol} ; R$ is the gas constant, $\mathrm{J} /(\mathrm{mol} \cdot \mathrm{K}) ; T_{G}$ is the gas temperature, $\mathrm{K}$.

\subsection{Gaussian diffusion model}

In the accident leakage, the medium storage capacity in the storage tank is large, so the pressure change can be ignored when the accident leakage occurs, which is regarded as a continuous leakage ${ }^{[12]}$, and the Gaussian plume model is used to simulate the forward diffusion. The equation of the standard Gaussian plume model is as follows ${ }^{[13]}$ :

$$
\begin{array}{r}
\mathrm{C}(\mathrm{x}, \mathrm{y}, \mathrm{z})=\frac{\mathrm{Q}}{2 \pi \mathrm{u} \sigma_{\mathrm{y}} \sigma_{\mathrm{z}}} \exp \left(-\frac{\mathrm{y}^{2}}{2 \sigma_{\mathrm{y}}^{2}}\right)\left\{\exp \left(-\frac{(\mathrm{z}-\mathrm{He})^{2}}{2 \sigma_{\mathrm{z}}^{2}}\right)+\right. \\
\left.\exp \left(\frac{(\mathrm{z}+\mathrm{He})^{2}}{2 \sigma_{\mathrm{z}}^{2}}\right)\right\}
\end{array}
$$

\subsection{Source inversion model}

In the process of source information inverse calculation, the objective function based on the square sum of concentration deviation is generally used to establish the inverse calculation model, and the objective function is shown in (3) ${ }^{[14]}$ :

$$
\text { function }=\min \left(\sum_{i=1}^{n}\left(C_{o b s}^{i}-C_{c a l}^{i}\right)^{2}\right)
$$

The setting of fixed monitoring points is shown in Figure 1. Point $\mathrm{O}$ is the actual leakage source. The monitoring points can be arranged at intervals of $1-5$, so $\mathrm{O}^{\prime}$ is the new coordinate. In the reverse calculation, it is required to calculate the location and source strength of leakage source point o through the set effective monitoring points.

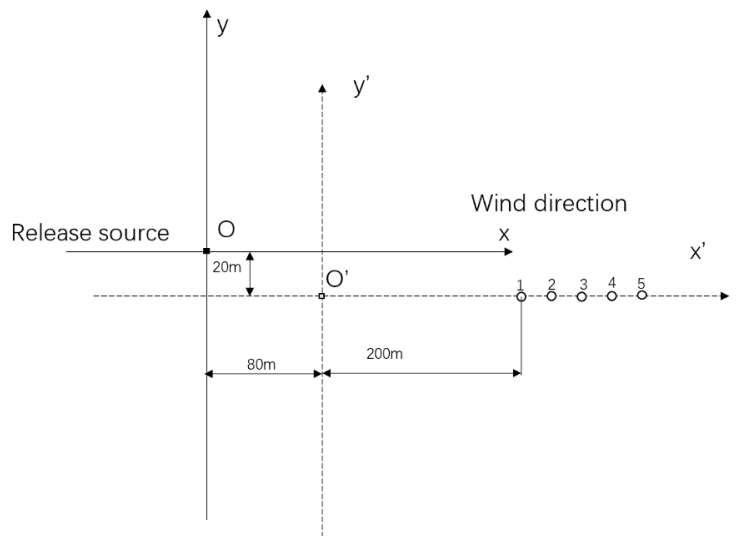

Figure 1. Fixed monitoring point setting

\section{Results and analysis}

\subsection{Simulation scenario of liquid ammonia leakage}

Suppose a liquid ammonia tank leaks at the top, the actual storage pressure is $1.6 \mathrm{MPa}$, the leakage height is $2.5 \mathrm{~m}$, the leakage port is vertical to the ground, the standard atmospheric pressure is $\quad 0.1013 \mathrm{MPa}$, the gas leakage rate is $4.12 \mathrm{~kg} / \mathrm{s}$, and the ambient wind speed at $2 \mathrm{~m}$ is 2.5 $\mathrm{m} / \mathrm{s}$. The concentration of monitoring points selected by reverse calculation is shown in Table 2 . For the height of flue gas lift, Wilson model is widely used, which is the empirical formula (4) obtained by Wilson ${ }^{[14]}$ according to the pipeline rupture leakage experiment, and the effective source height is $27.65 \mathrm{~m}$. 
$\Delta H=2.4 V_{s} D / u(4)$

Where $V s$ is the gas cloud release rate, $\mathrm{m} / \mathrm{s} ; D$ is the diameter of leakage port, $\mathrm{m}$.

Table 2. Monitoring point concentration.

\begin{tabular}{ccc}
\hline Serial number & Coordinate & Concentration $(\mathrm{mg} / \mathrm{s})$ \\
\hline 1 & $(280,-20,2)$ & 155.8 \\
2 & $(330,-20,2)$ & 201.6 \\
3 & $(380,-20,2)$ & 224.7 \\
4 & $(430,-20,2)$ & 231.6 \\
5 & $(480,-20,2)$ & 228.5 \\
\hline
\end{tabular}

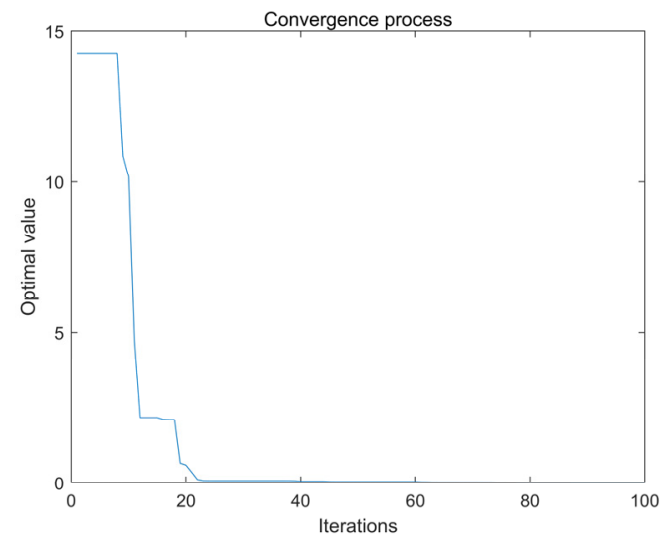

Optimal solution of adaptive function

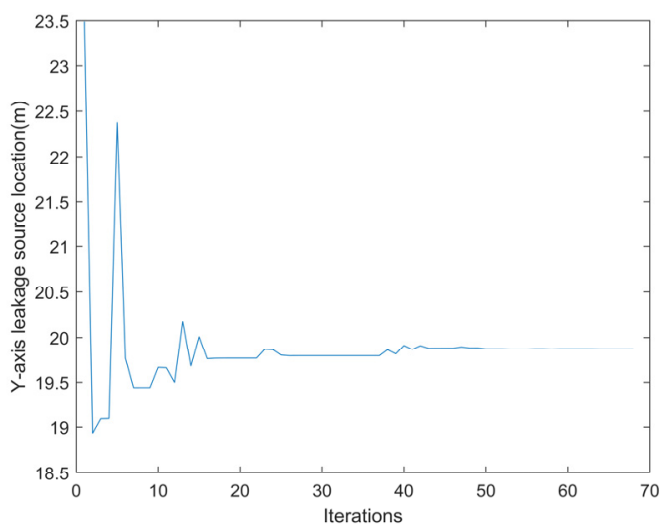

Source item location ( $\mathrm{Y}$-axis)
The results of source term back calculation are shown in Table 3. The iterative diagram of each parameter is shown in Figure 2.

Table 3. Back calculation results

\begin{tabular}{cccc}
\hline Parameter & True value & $\begin{array}{c}\text { Back } \\
\text { calculation } \\
\text { result }\end{array}$ & $\begin{array}{c}\text { Relative } \\
\text { error/\% }\end{array}$ \\
\hline $\mathrm{Q}(\mathrm{kg} / \mathrm{s})$ & 4.12 & 4.1011 & 0.46 \\
\hline $\mathrm{X}(\mathrm{m})$ & -80 & -79.5921 & 0.50 \\
\hline $\mathrm{Y}(\mathrm{m})$ & 20 & 19.8726 & 0.16 \\
\hline
\end{tabular}

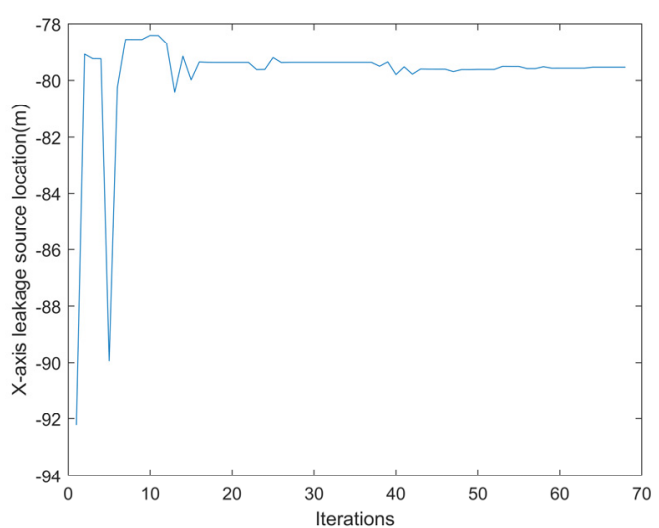

Source item location ( $\mathrm{X}$-axis)

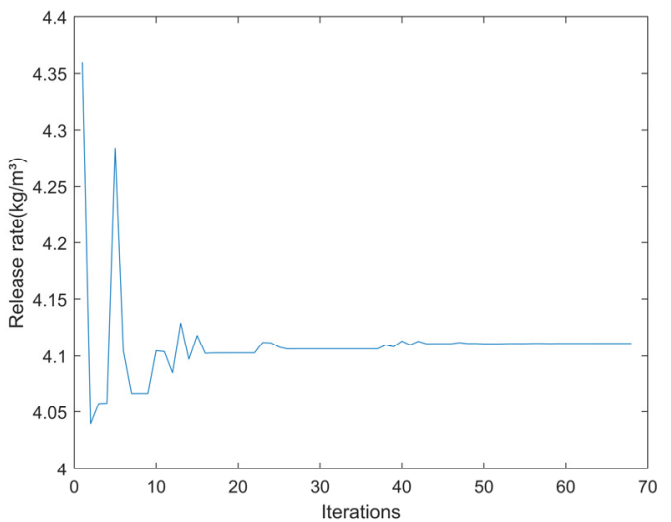

Release rate

Figure 2. Fixed monitoring point setting

The results in Table 3 and Figure 2 show that point $O$ is at the junction of $-80 \mathrm{~m}$ of $\mathrm{X}$-axis and $20 \mathrm{~m}$ of $\mathrm{Y}$-axis of point $\mathrm{O}^{\prime}$, and the relative error of location information and source intensity back calculation is less than $0.5 \%$. It can accurately calculate the location of the source term of liquid ammonia leakage, and verify the feasibility of particle swarm optimization algorithm in the source term back calculation of liquid ammonia tank leakage accident, which can provide guidance for the emergency rescue of liquid ammonia leakage accident.

\section{Conclusions}

Through the analysis of the physical and chemical properties of ammonia, combined with the leakage characteristics of liquid ammonia storage tank, combined with the leakage source model to calculate the leakage rate, and combined with Wilson model to modify the smoke lifting height of standard Gaussian plume model, so as to make it more in line with the actual situation of liquid ammonia storage tank leakage.

Based on the source model term back calculation selected five points concentration established analog monitor, PSO can quickly search item information source, the relative error is less than $0.5 \%$, verified that the method is applicable to liquid ammonia storage tank. The feasibility of back calculation of the source term under accidental leakage. 


\section{Acknowledgments}

This work was supported by National Key Research and Development Program of China (No.2018YFC0809300).

\section{References}

1. Zheng X., Chen Z. Inverse calculation approaches for source determination in hazardous chemical releases[J]. Journal of Loss Prevention in the Process Industries, 2011, 24(4):293-301.

2. Pan X., Jiang J. Analysis on important release accidents and modes studying[J]. Chemical Industry and Engineering, 2002 (03): 248-252 + 264.

3. Daniel, A.C., Joseph, F.L. (2002). Chemical process safety fundamentals with applications (2nd ed.). New Jersey: Prentice-Hall.

4. He P., Zheng B., Zheng J. Urban PM(2.5) Diffusion Analysis Based on the Improved Gaussian Smoke Plume Model and Support Vector Machine[J]. Aerosol and Air Quality Research, 2018, 18(12):3177-3186.

5. Zhang Q., Guo R.P., Zhang C.M., et al. Radioactive airborne effluents and the environmental impact assessment of CAP1400 nuclear power plant under normal operation[J]. Nuclear Engineering and Design, 2014.

6. Lee B., Cho S., Lee S.K., et al. Development of a Smoke Dispersion Forecast System for Korean Forest Fires[J]. Forests, 2019, 10(3): 219.

7. Efthimiou G.C., Andronopoulos S., Tavares R., et al. CFD-RANS prediction of the dispersion of a hazardous airborne material released during a real accident in an industrial environment[J]. Journal of Loss Prevention in the Process Industries, 2017, 46: 23-36.

8. Kumar, Pramod. CFD simulation of short-range plume dispersion from a point release in an urban like environment[J]. Atmospheric Environment, 2015.

9. Lin, Y., Chen G., Chen, T., et al. The influence of advertisement boards, street and source layouts on $\mathrm{CO}$ dispersion and building intake fraction in threedimensional urban-like models[J]. Building and Environment, 2019, 150(MAR.): 297-321.

10. Monache L., Lundquist J.K., Kosovic B., et al. Bayesian Inference and Markov Chain Monte Carlo Sampling to Reconstruct a Contaminant Source on a Continental Scale[J]. Journal of Applied Meteorology \& Climatology, 2008, 47(10): 2600-2613.

11. Zheng X., Chen Z. Inverse calculation approaches for source determination in hazardous chemical releases[J]. Journal of Loss Prevention in the Process Industries, 2011, 24(4): 293-301.

12. Ma D., Fang J., Qian Y. Simulation study on the leakage diffusion of liquid ammonia tank[J]. Journal of Transport Science and Engineering, 2017, 33(02): 66-70+84.

13. Stockie J.M. The mathematics of atmospheric dispersion modelling[J]. SIAM Review, 2011, 53: 349-372.

14. Chen Z. Study on the location of hazardous chemicals leakage source[D]. Beijing University of Chemical Technology, 2013. 